\title{
Dynamic Inventory and Pricing Policy in a Periodic-Review Inventory System with Finite Ordering Capacity and Price Adjustment Cost
}

\author{
Baimei Yang, ${ }^{1}$ Chunyan Gao, ${ }^{2} \mathrm{Na} \mathrm{Liu},{ }^{3}$ and Liang $\mathrm{Xu}^{4}$ \\ ${ }^{1}$ School of Business, Shanghai Dianji University, Shanghai 201306, China \\ ${ }^{2}$ Department of Management Science, Southwestern University of Finance and Economics, Chengdu 611130, China \\ ${ }^{3}$ Business School, Beijing Institute of Fashion Technology, Beijing 100029, China \\ ${ }^{4}$ Department of Logistics Management, Southwestern University of Finance and Economics, Chengdu 611130, China
}

Correspondence should be addressed to Na Liu; nanalaufashion@gmail.com

Received 23 April 2015; Accepted 21 September 2015

Academic Editor: Ruihua Liu

Copyright (C) 2015 Baimei Yang et al. This is an open access article distributed under the Creative Commons Attribution License, which permits unrestricted use, distribution, and reproduction in any medium, provided the original work is properly cited.

\begin{abstract}
We consider a dynamic inventory control and pricing optimization problem in a periodic-review inventory system with price adjustment cost. Each order occurs with a fixed ordering cost; the ordering quantity is capacitated. We consider a sequential decision problem, where the firm first chooses the ordering quantity and then the sale price to maximize the expected total discounted profit over the sale horizon. We show that the optimal inventory control is partially characterized by a $\left(s, s^{\prime}, p\right)$ policy in four regions, and the optimal pricing policy is dependent on the inventory level after the replenishment decision. We present some numerical examples to explore the effects of various parameters on the optimal pricing and replenishment policy.
\end{abstract}

\section{Introduction}

Traditional literature on the multistage inventory system mainly focuses on replenishment decision with or without setup cost. The well-known result is that the order-up-to policy is optimal for the systems without setup cost and the $(s, S)$ policy is optimal for the systems with setup cost. Increasing researchers are devoted to the study of joint price and inventory control in the multistage inventory system. Our paper belongs to this stream, but our paper considers a sequential decision problem in a periodic-review inventory system with fixed ordering cost and price adjustment cost. The ordering quantity is capacitated; this may be limited by the storage capacity or the supply capability. The firm first decides its inventory level and then chooses a sale price to maximize its long-run profit. Our result shows that the optimal inventory and pricing decision still preservers a threshold-type structure.

Our paper is related to literature on the optimal control of a single product system with finite capacity and setup cost.
Several studies have been devoted to this area. Shaoxiang and Lambrecht [1] obtain the generally known result; that is, the optimal policy can only be partially characterized in the form of $X-Y$ bands. In particular, when the inventory level is below the first band $X$, then produce/order the capacity, and when the inventory level is over the second band $Y$, produce/order nothing. If the inventory level is between the two bands, the ordering policy is complicated and depends on the instance. Gallego and Scheller-Wolf [2] extend their work. They derive the structure of the policy between the bands. The optimal policy is characterized by two numbers $s$ and $s^{\prime}$ which divide the state space into four possible regions. However, none of them have studied the pricing problem in the inventory control problem. Zhang et al. [3] consider a single-item, finite-horizon, periodic-review coordinated decision model on pricing and inventory control with capacity constraints and fixed ordering cost. They show that the profit-to-go function is strongly $C K$-concave, and the optimal policy has an $(s, S, P)$-like structure. However, the price adjustment cost has not been addressed. Chao et al. [4] recently consider 
the joint pricing and inventory decisions. They study a periodic-review inventory system with setup cost and finite ordering capacity in each period. They show that the optimal inventory control is characterized by an $\left(s, s^{\prime}, p\right)$ policy in four regions of the starting inventory level. However, in their paper, the selling price can be adjusted without any cost.

In reality, changing price is costly and incurs a price adjustment cost. In the economics literature, there are two major types of price adjustment costs: the managerial costs and the physical costs. Rotemberg [5], Levy et al. [6], Slade and Groupe de Recherche en Economie Quantitative d'AixMarseille [7], Aguirregabiria [8], Bergen et al. [9], and Zbaracki et al. [10] have stated that both types of costs are significant in retailing and other industries. According to these empirical studies, Chen et al. [11] consider a periodicreview inventory model with price adjustment cost. The price adjustment cost consists of both fixed and variable components. They develop the general model and characterize the optimal policies for two special scenarios, a model with inventory carryover and no fixed price-change costs and a model with fixed price-change costs and no inventory carryover. Although there is price adjustment cost, they do not consider the finite ordering capacity.

Under the assumption of random additive demand model, our paper tries to investigate the structure of the optimal inventory control and pricing policy in each period. We show that the optimal inventory policy is partially characterized by an $\left(s, s^{\prime}, p\right)$ policy on four regions; in two of these regions the optimal policy is completely specified while, in the other two, it is partially specified. More specifically, the optimal ordering quantity in the first region is the full capacity, while in the last region it is optimal to order nothing; in the two middle regions, the optimal decision is either to order to the maximum capacity, to order to at least a prespecified level $s^{\prime}$, or to order nothing. The optimal pricing policy $p(y)$ in each period is dependent on the inventory level after the replenishment decision, $y$, which is in general not a monotone function. The key concept utilized is strong $C K$ concavity, which is an extension of $K$-concavity, and was first introduced by Gallego and Scheller-Wolf [2].

The rest of this paper is organized as follows. In Section 2, we induce the model description. The structural properties of the optimal inventory and pricing policy are characterized in Section 3. We present some numerical examples to show the effects of various parameters on the optimal control policy in Section 4. Finally, we conclude with some future research direction in Section 5.

\section{The Model}

Consider a periodic-review inventory system with finite ordering capacity and price adjustment cost. There are $N$ periods, with the first period being 1 and last period being $N$. In each period, the sequence of events is given as follows: (1) inventory level is reviewed and replenishment order is placed; (2) replenishment order arrives; (3) a selling price is set; (4) random demand is realized; and (5) all costs are computed.
In period $n$, the selling price is $p_{n}$, which is taken in interval $\left[p_{l}, p_{h}\right]$, and the demand is $D_{n}$. We assume that the demand $D_{n}$ is sensitive to the selling price $p_{n}$. Moreover, we consider an additive demand function. The demand function is $D_{n}\left(p_{n}\right)=d\left(p_{n}\right)+\epsilon_{n}, n=1, \ldots, N$, where $\epsilon_{n}$ is a random variable with mean zero and $d\left(p_{n}\right)$ is the average demand. Furthermore, $d\left(p_{n}\right)$ is a decreasing linear function of $p_{n}$. When the selling price $p_{n}$ increases from $p_{l}$ to $p_{h}$, the average demand decreases from $d_{h}$ to $d_{l}$; that is, $d_{h}=d\left(p_{l}\right)$ and $d_{l}=d\left(p_{h}\right)$. Each demand arrives requiring only one unit of product and is satisfied from inventory if any. If the demand cannot be satisfied from the on-hand inventory immediately, then it is backlogged and incurs a backorder cost. The structure of demand function indicates that determining the selling price $p_{n}$ is equivalent to setting the average demand $d_{n}$.

Each replenishment incurs a fixed ordering cost $K$ and the variable unit ordering cost $c$. There is a finite ordering capacity $C$ for each period, which means the ordering quantity in each period cannot exceed $C$, where $C>0$. If $C$ is sufficiently large, it generalizes to the incapacitated case. Let $x_{n}$ be the inventory level at the beginning of period $n$ before placing an order and let $y_{n}$ be the inventory level after the order delivered. At the end of each period, the demand is realized and a revenue is received. The expected revenue is given by $r_{n}(d)=d_{n} \cdot p_{n}\left(d_{n}\right)$, which is assumed to be a concave function. Meanwhile, an inventory holding and shortage cost occurs denoted by $h\left(y_{n}-d_{n}\right)$. If $x \geq 0, h(x)$ represents the holding cost; if $x<0, h(x)$ represents the shortage cost. For ease of presentation, we let $G(y)=E\left[h\left(y-\epsilon_{n}\right)\right]$. Therefore, given that the inventory level after replenishment is $y_{n}$ and the expected demand for period $n$ is $d_{n}$, the expected holding and shortage cost is $G\left(y_{n}-d_{n}\right)$.

We assume that there is a fixed guide price $p_{0}$ for deciding the selling price $p_{n}$. Price changing from the guide price to the actual price is costly. The cost of a price adjustment from guide price to the actual selling price in period $n$ is denoted by $U_{n}\left(p_{n}-p_{0}\right)$. Zbaracki et al. [10] and Chen et al. [11] pointed out that as the price adjustment cost becomes larger, it would cost more on decision and internal communication. Here, we assume that the variable cost $U_{n}(\cdot)$ is convex and increases with $\left|p_{n}-p_{0}\right|$. The forms of $U_{n}(\cdot)$ could be either piecewise linear functions or quadratic functions. The ordering quantity in period $n$ is $y_{n}-x_{n}$; therefore, we have $x_{n} \leq y_{n} \leq x_{n}+C$ due to the capacitated ordering quantity $C$. Therefore, the expected total cost incurs in period $n$ including setup cost, ordering cost, holding and shortage cost and price adjustment price is given by

$$
\begin{aligned}
& K 1\left[y_{n}>x_{n}\right]+c\left(y_{n}-x_{n}\right)+G\left(y_{n}-d_{n}\right) \\
& \quad+U_{n}\left(p_{n}-p_{0}\right),
\end{aligned}
$$

where $1[A]$ is the indicating function taking value 1 if statement $A$ is true and zero otherwise.

We aim to obtain the optimal pricing and inventory decisions in each period to maximize the expected total discounted profit over the $n$ periods. Let $V_{n}(x)$ denote the maximum expected total discounted profit from period $n$ to 
the end of the planning horizon with the starting inventory level (before ordering decision) $x$. The optimality equation is

$$
\begin{aligned}
& V_{n}(x)=\max _{x \leq y \leq x+C} \max _{p \in\left[p_{l}, p_{h}\right]}\{-K 1[y>x]+r(p) \\
& -c(y-x)-G(y-d)-U\left(p-p_{0}\right) \\
& \left.\quad+\alpha E\left[V_{n+1}\left(y-d(p)-\epsilon_{n}\right)\right]\right\}
\end{aligned}
$$

where $\alpha$ is the one-period discount factor, $\alpha \in[0,1]$. The terminal condition is $V_{N+1}(x) \equiv 0$. Note that the price $p_{n}$ can be indicated in the form of demand $d_{n}$ by the inverse demand function; that is, $p_{n}=p_{n}\left(d_{n}\right)$, and the price adjustment cost can be written in the form of $d_{n}$ instead of $p_{n}$, that is, $U_{n}\left(d_{n}-p_{0}\right)$, such that optimizing over the selling price $p_{n}$ is equivalent to optimizing over the average demand $d_{n}$. Therefore, the optimality equation is rewritten as follows:

$$
\begin{aligned}
& V_{n}(x)=\max _{x \leq y \leq x+C} \max _{d \in\left[d_{l}, d_{h}\right]}\{-K 1[y>x]+r(d) \\
& -c(y-x)-G(y-d)-U\left(d-p_{0}\right) \\
& \left.\quad+\alpha E\left[V_{n+1}\left(y-d-\epsilon_{n}\right)\right]\right\} .
\end{aligned}
$$

For notation convenience, we define another function

$$
W_{n}(y)=-G(y)+\alpha E\left[V_{n+1}\left(y-\epsilon_{n}\right)\right] .
$$

Then the optimality equation is further simplified to

$$
\begin{aligned}
& V_{n}(x)=c x+\max _{x \leq y \leq x+C} \max _{d \in\left[d_{l}, d_{h}\right]}\left\{-K 1[y>x]+r_{n}(d)-c y-U_{n}\left(d-p_{0}\right)+W_{n}(y-d)\right\}=c x \\
& +\max _{x \leq y \leq x+C}\left\{-K 1[y>x]-c y+\max _{d \in\left[d_{l}, d_{h}\right]}\left\{r_{n}(d)-U_{n}\left(d-p_{0}\right)+W_{n}(y-d)\right\}\right\} .
\end{aligned}
$$

\section{The Optimal Policy}

In order to characterize the structural properties of the optimal replenishment and pricing policy, we first introduce the definition of strongly $C K$-concave and properties of $C K$ concave functions as well, which is defined in Chao et al. [4]. This definition and the properties are very important in studying inventory models with finite capacity and setup cost.

Definition 1. A function $g(\cdot): R \rightarrow R$ is strongly $C K$ concave if, for all $a \geq 0, b>0$, and $z \in[0, C]$, we have

$$
\frac{z}{b} g(y-a)+g(y) \geq \frac{z}{b} g(y-a-b)+g(y+z)-K .
$$

The structure of strong $C K$-concave function is shown in Figure 1. If $G(x)$ is strong $C K$-concave, it implies that the slope of the line made of points $(x, G(x))$ and $(x+z, G(x+$ $z)-K)$ is smaller than the slope of the line made of points $(x-$ $a-b, G(x-a-b))$ and $(x-a, G(x-a))$.

Chao et al. [4] also pointed out that the strongly $C K$ concave function possesses some additional properties as follows:

(1) If $G$ is strongly $C K$-concave, then it is also strongly $D L$-concave for $0 \leq D \leq C$ and $L \geq K$.

(2) If $G$ is concave, it is also strongly $C K$-concave for any nonnegative $C$ and $K$.

(3) If $G_{1}$ is strongly $C K_{1}$-concave and $G_{2}$ is strongly $C K_{2}$ concave, then for $\alpha, \beta \geq 0, \alpha G_{1}+\beta G_{2}$ is strongly $C\left(\alpha K_{1}+\beta K_{2}\right)$-concave.

(4) If $G$ is strongly $C K$-concave and $X$ is a random variable such that $E[|G(y-X)|]<\infty$, then $E[G(y-$ $X)]$ is also strongly $C K$-concave.

In the following, we aim to show that $V_{n}(x)$ preservers the property of strong $C K$-concavity. Before going further, we first show that each term on the right hand side of (3) possesses some certain properties, which will facilitate our analysis of objective function $V_{n}(x)$.

Lemma 2. $U_{n}\left(d-p_{0}\right)$ is convex in $d$.

Proof. Considering that $U_{n}\left(d-p_{0}\right)$ is continuous and secondorder derivable, the convexity of $U_{n}\left(d-p_{0}\right)$ can be proved by its second derivative. We have

$$
\begin{aligned}
\frac{d U_{n}\left(d-p_{0}\right)}{d d}= & \frac{d U_{n}\left(p-p_{0}\right)}{d p} \frac{d p(d)}{d d} \\
\frac{d^{2} U_{n}\left(d-p_{0}\right)}{d d^{2}}= & \frac{d^{2} U_{n}\left(p-p_{0}\right)}{d p^{2}}\left(\frac{d p(d)}{d d}\right)^{2} \\
& +\frac{d U_{n}\left(p-p_{0}\right)}{d p} \frac{d^{2} p(d)}{d d^{2}} .
\end{aligned}
$$

Since $d\left(p_{n}\right)$ is linear and decreasing on $p_{n}$, which means $p\left(d_{n}\right)$ is also linear and decreasing on $d_{n}$, then $d^{2} p(d) / d d^{2}=0$. At the same time, due to the convexity of $U_{n}(\cdot), d^{2} U_{n}(p-$ $\left.p_{0}\right) / d p^{2} \geq 0$. Therefore,

$$
\frac{d^{2} U_{n}\left(d-p_{0}\right)}{d d^{2}}=\frac{d^{2} U_{n}\left(p-p_{0}\right)}{d p^{2}}\left(\frac{d p(d)}{d d}\right)^{2} \geq 0
$$

which indicates that $U_{n}\left(d-p_{0}\right)$ is convex in $d$. Lemma 2 is proved.

Lemma 3. Let $d_{n}(y)$ be the maximizer of $r_{n}(d)-U_{n}\left(d-p_{0}\right)+$ $W_{n}(y-d)$; then $y-d_{n}(y)$ is increasing in $y$.

Proof. Due to the concavity of $r(\cdot)$ and Lemma 2, Lemma 3 can be conducted directly by using the properties of supermodularity. 


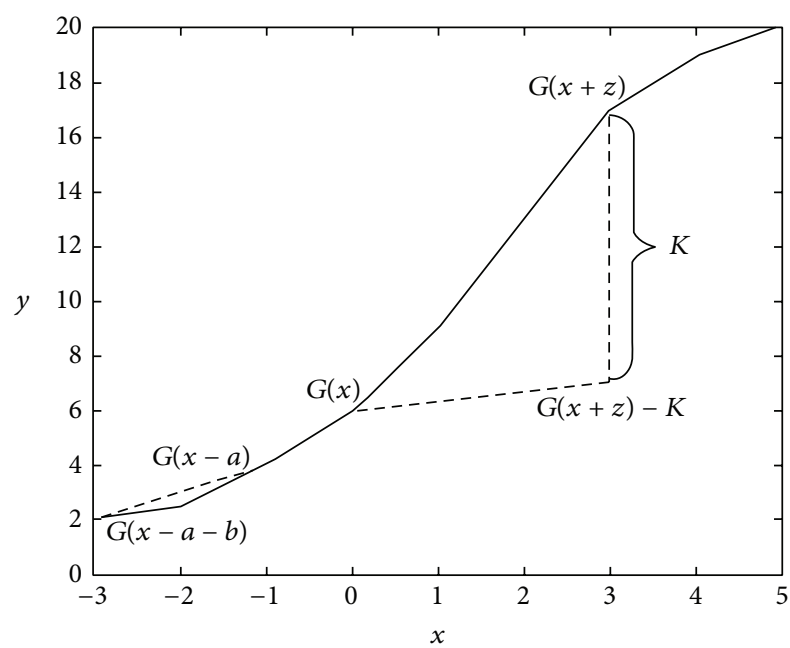

Figure 1: $C K$-concave function.

Lemma 4. If $W_{n}(y)$ is strongly $C K$-concave, then

$$
g(y)=\max _{d \in\left[d_{l}, d_{h}\right]}\left\{r_{n}(d)-U_{n}\left(d-p_{0}\right)+W_{n}(y-d)\right\}
$$

is also strongly CK-concave.

The proof of Lemma 4 is similar to that in Chao et al. [4]. We omit it for simplicity.

\section{Lemma 5. $V_{n}(x)$ is strongly $C K$-concave.}

Proof. Lemma 5 can be proved by induction. When $n=N+1$, we have $V_{N+1} \equiv 0$, such that $V_{N+1}$ is strongly $C K$-concave. Now suppose that $V_{n+1}(x)$ is strongly $C K$-concave; then we proceed to prove that $V_{n}(x)$ is also strongly $C K$-concave.

Due to the property of strong $C K$-concavity, we obtain that $\alpha E\left[V_{n+1}\left(y-\epsilon_{n}\right)\right.$ is strongly $C(\alpha K)$-concave. Consider that $-G_{n}(y)$ is concave; then $W_{n}(y)$ is strongly $C(\alpha K)$-concave, which is also strongly $C K$-concave. Lemma 4 shows that $g(y)$ is also strongly $C K$-concave. Therefore,

$$
V_{n}(x)=c x+\max _{x \leq y \leq x+C}\{-K 1[y>x]-c y+g(y)\}
$$

is also strongly $C K$-concave. Readers are referred to Gallego and Scheller-Wolf [2] for more details. Lemma 5 is concluded.

The strong $C K$-concavity of $V_{n}(x)$ characterizes the structural properties of the optimal inventory and pricing policy for each period as given in the following theorem.

Theorem 6. Suppose that $x$ is the starting inventory level at the beginning of period $n$. The optimal inventory policy is thresholdtype policy which is characterized by two numbers $s_{n}$ and $s_{n}^{\prime}$, where $s_{n} \leq s_{n}^{\prime}$. Furthermore, the optimal inventory policy possesses the following additional properties:

(a) If $s_{n}^{\prime}-C \leq s_{n}$, then the optimal ordering policy is

(i) order capacity $C$ if $x<s_{n}^{\prime}-C$; (ii) order at least up to $s_{n}^{\prime}$ if $s_{n}^{\prime}-C \leq x<s_{n}$;

(iii) either order nothing or order at least up to $s_{n}^{\prime}$ if $s_{n} \leq x<s_{n}^{\prime} ;$

(iv) order nothing if $x \geq s_{n}^{\prime}$.

(b) If $s_{n}^{\prime}-C>s_{n}$, then the optimal ordering policy is

(i) order capacity $C$ if $x<s_{n}$;

(ii) either order nothing or order $C$ if $s_{n} \leq x<s_{n}^{\prime}-C$;

(iii) either order nothing or order at least up to $s_{n}^{\prime}$ if $s_{n}^{\prime}-C \leq x<s_{n}^{\prime}$;

(iv) order nothing if $x \geq s_{n}^{\prime}$.

The optimal pricing decision is characterized by $p_{n}^{*}(y)$, which depends on the postorder inventory position y. Furthermore, the optimal pricing decision $p_{n}^{*}(y)$, as well as the optimal average demand $d_{n}^{*}(y)$, is in general not monotone in $y$.

Proof. Suppose

$$
\begin{aligned}
& H_{n}(y) \\
& =-c y \\
& +\max _{d \in\left[d_{l}, d_{h}\right]}\left\{r_{n}(d)-U_{n}\left(d-p_{0}\right)+W_{n}(y-d)\right\} .
\end{aligned}
$$

Define $s_{n}, S_{n}$, and $s_{n}^{\prime}$ by

$$
\begin{aligned}
& S_{n}=\inf \left\{y \in R \mid G(y)=\sup _{y \in R} H_{n}(y)\right\}, \\
& s_{n}=\inf \left\{x \mid-K+\sup _{x \leq y \leq x+C} H_{n}(y) \leq H_{n}(x)\right\}, \\
& s_{n}^{\prime}=\max \left\{x \leq S_{n} \mid-K+\sup _{x \leq y \leq x+C} H_{n}(y) \geq H_{n}(x)\right\} .
\end{aligned}
$$

Obviously, $s_{n} \leq s_{n}^{\prime}$.

The optimal pricing decision is determined by the maximizer in Lemma 4. Let

$$
\begin{aligned}
& d_{n}^{*}(y) \\
& \quad=\arg \max _{d \in\left[d_{l}, d_{h}\right]}\left\{r_{n}(d)-U_{n}\left(d-p_{0}\right)+W_{n}(y-d)\right\},
\end{aligned}
$$

which means that the optimal average demand in period $n$ depends on the replenished inventory level $y$. Since $p=p(d)$ is the inverse function of $d=d_{n}(p)$, then we will obtain that the optimal pricing decision is

$$
p_{n}^{*}(y)=p\left(d_{n}^{*}(y)\right)
$$

when the replenished inventory level is $y$. Therefore, the optimal selling price in period $n$ also depends on the replenished inventory level $y$. However, $p_{n}^{*}(y)$ is not monotone in $y$. We will give one example in Section 4. The proof of Theorem 6 is concluded. 


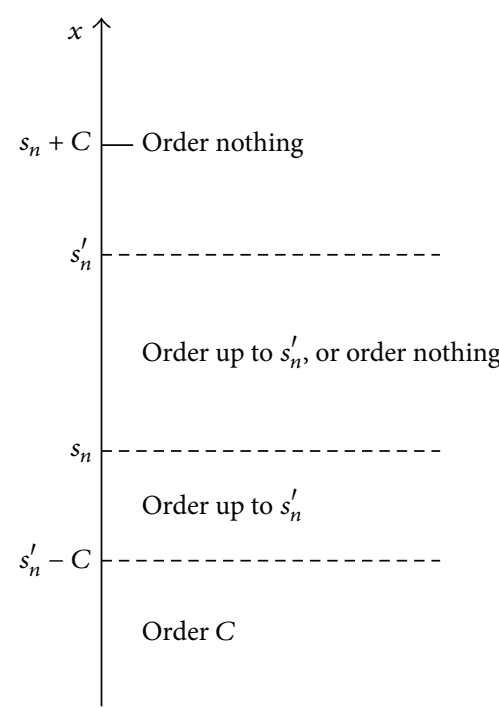

(a) $s_{n}^{\prime}-C \leq s_{n}$

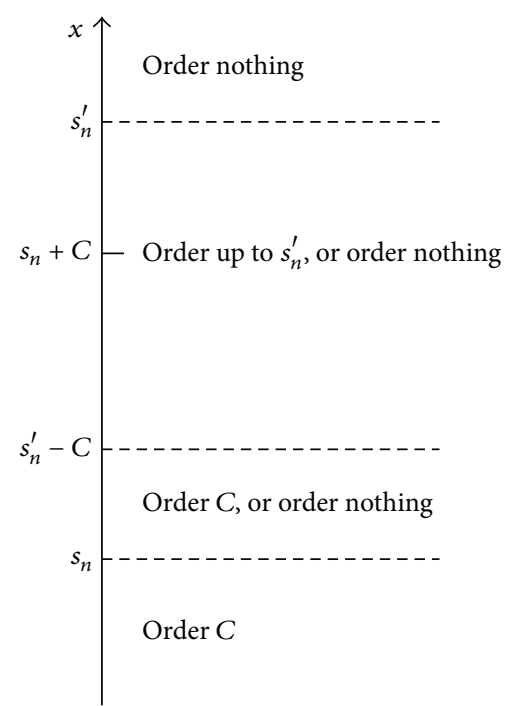

(b) $s_{n}^{\prime}-C>s_{n}$

FIgURE 2: The structure of the optimal replenishment policy.

The structure of the optimal inventory policy is presented in Figure 2.

Our results are similar to Gallego and Scheller-Wolf [2] in that the optimal inventory policy can only be partially characterized. When the inventory level before replenishment $x$ is less than $\min \left\{s_{n}^{\prime}-C, s_{n}\right\}$, the optimal ordering policy is to order the full capacity. When $x$ is larger than $s_{n}^{\prime}$, the optimal ordering policy is no order. When $\min \left\{s_{n}^{\prime}-C, s_{n}\right\} \leq x<s_{n}^{\prime}$, the optimal strategy is complicated. When $\max \left\{s_{n}^{\prime}-C, s_{n}\right\} \leq$ $x<s_{n}^{\prime}$, the optimal strategy may be to either order nothing or order at least up to $s_{n}^{\prime}$. When $\min \left\{s_{n}^{\prime}-C, s_{n}\right\} \leq x<\max \left\{s_{n}^{\prime}-\right.$ $\left.C, s_{n}\right\}$, there would be two possibilities. If $s_{n}^{\prime}-C \leq s_{n}$, the optimal policy is to order at least up to $s_{n}^{\prime}$. If $s_{n}^{\prime}-C>s_{n}$, the optimal policy is no order or ordering full capacity. Moreover, the optimal pricing decision depends on the inventory level after replenishment.

\section{Numerical Tests}

In order to explore the effects of the setup cost, the ordering capacity, the guide price, and the adjustment cost function on the optimal control policy, we conduct several numerical experiments for a simple inventory problem with $N=4$ periods. In the subsequent numerical experiments, we use the following basic settings: the discount factor is $\alpha=0.9$, purchasing unit cost $c=3$, guide price $p_{0}=3$, ordering capacity $C=10$, and setup cost $K=10$. We adopt $h(x)=$ $h \max \{0, x\}+b \max \{0,-x\}$ as the holding shortage cost rate function, where $h=2$ and $b=4$. Suppose that $U_{n}(\cdot)$ is piecewise linear, which means that $U_{n}\left(p-p_{0}\right)=a_{1} \max \left\{p_{0}-\right.$ $p, 0\}+a_{2} \max \left\{p-p_{0}, 0\right\}$, where $a_{1}=a_{2}=0.5$. The demand in period $n$ is $D_{n}\left(p_{n}\right)=d\left(p_{n}\right)+\epsilon_{n}$, where $d\left(p_{n}\right)=10-p_{n}$ and random error $\epsilon_{n} \in\{-1,1\}$, with probability mass function $P\left\{\epsilon_{n}=1\right\}=P\left\{\epsilon_{n}=-1\right\}=0.5$. Here, $p_{n}$ takes values in

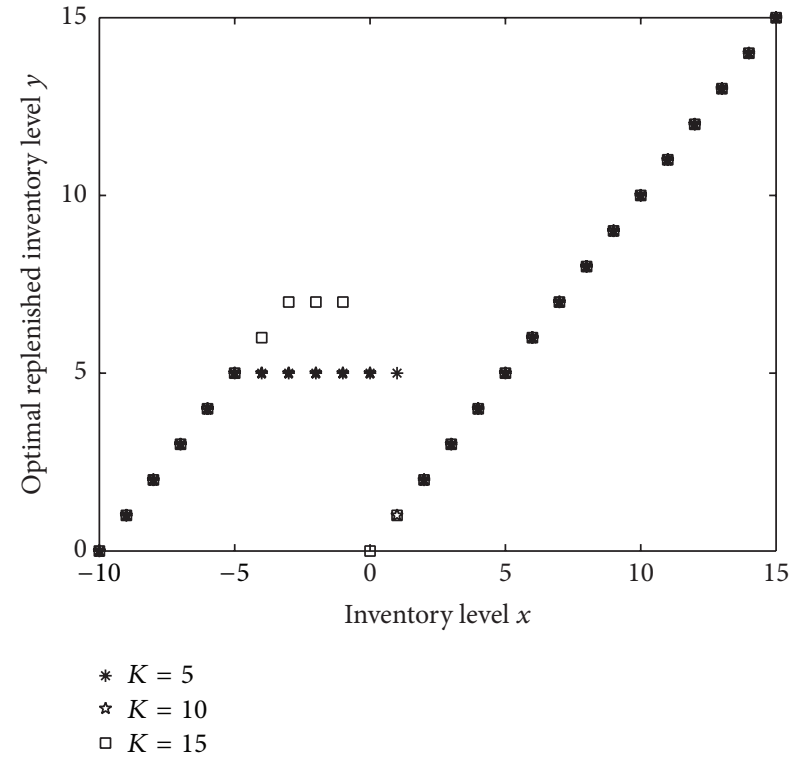

FIGURE 3: Optimal replenished inventory level $y$ for different $K$.

$[1,9]$. Thus, as $p_{n}$ increases from 1 to 9 , the average demand decreases from 9 to 1 .

4.1. Effect of Setup Cost. We study the effect of the setup cost $K$ on the optimal inventory and pricing policy. The results are shown in Figures 3 and 4 . In Figure 3, the $x$-axis represents the inventory level before ordering $x$ and $y$-axis represents the inventory level after ordering $y$. The value of $x$ goes from -10 to 15 , with the increment of 1 . In Figure 4 , the $x$-axis represents the inventory level before ordering $x$ and $y$-axis represents the optimal selling price $p$. The value of $x$ also goes 


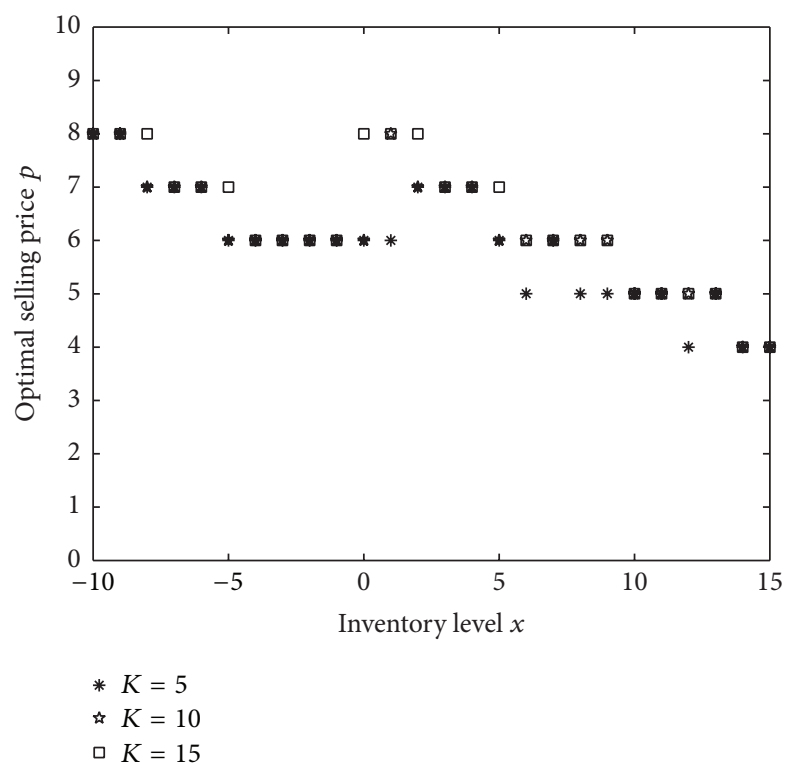

Figure 4: Optimal selling price $p$ for different $K$.

from -10 to 15 , with the increment of 1 . Here, we consider $K=5, K=10$, and $K=15$ separately.

Figure 3 shows that the higher setup cost $K$ implies lower inventory level at which the optimal ordering policy changes from ordering to not ordering, while Figure 4 shows that the higher setup cost indicates higher optimal selling price. The results are intuitive. The trade-off is the setup cost, holding cost, and sale revenue. When the setup cost is high, we will decrease the replenishment frequency in order to reduce the ordering cost. Hence, we would place no order at low inventory level and order up to a higher inventory level if we place an order. The other alternative way is to increase the selling price to reduce the demand, in the purpose of saving setup cost.

Observation 1. The optimal selling price $p$ is not always monotonic in $y$.

When $K=5$ and the inventory level before ordering $x$ is no less than 2, the optimal replenished inventory level $y$ is equal to $x$. Furthermore, in Figure 4, when $K=5$ and $x \geq 2$, the optimal selling price $p$ is not monotonic in $x$; in other words, $p$ is not monotonic in $y$.

4.2. Effect of Ordering Capacity. The effects of ordering capacity $K$ on the optimal inventory and pricing policy are shown in Figures 5 and 6. Higher ordering capacity means that we may order more every time without increasing cost. Particularly, when the inventory level is high enough, the optimal policy is not to order. Then the ordering capacity has no effect on the optimal ordering policy and selling price. When the inventory level is small, higher ordering capacity indicates higher optimal replenished inventory level and lower optimal selling price, which induces higher demand.

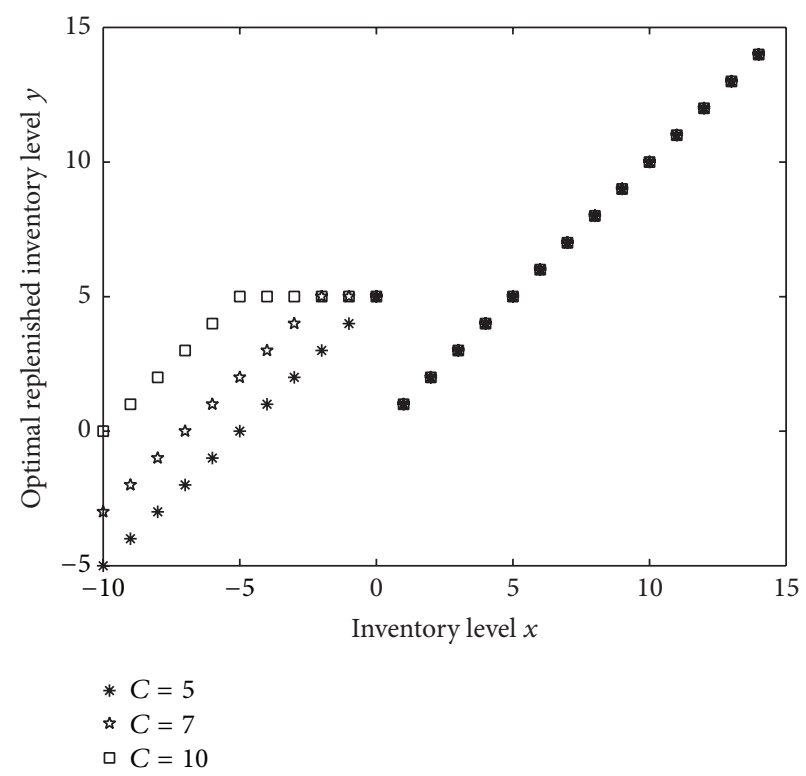

FIGURE 5: Optimal replenished inventory level $y$ for different $C$.

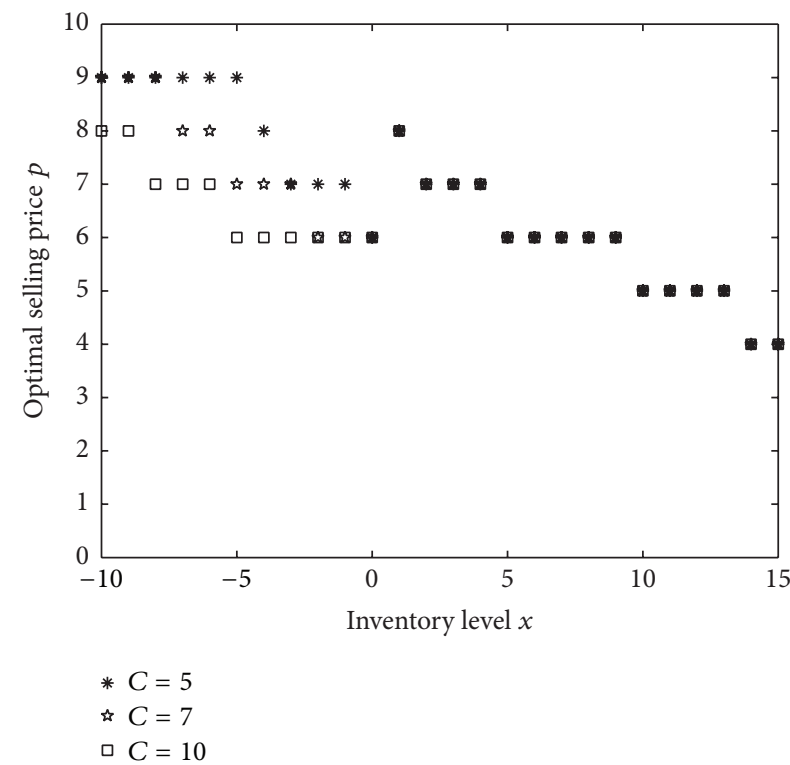

FIgURE 6: Optimal selling price $p$ for different $C$.

4.3. Effect of Guide Price. The effects of guide price $p_{0}$ on the optimal inventory and pricing policy are shown in Figures 7 and 8. Compared with no guide price, the existence of the guide price indicates higher inventory level at which the optimal ordering policy changes from ordering to not ordering. The guide price has no obvious effect on the optimal replenishment inventory level, but it influences the optimal selling price. The optimal selling price would be closer to the guide price compared with the initial optimal selling price without guide price. For instance, when the guide price is 5, the optimal selling price would be lower than the initial one under small inventory level, while the optimal selling price 


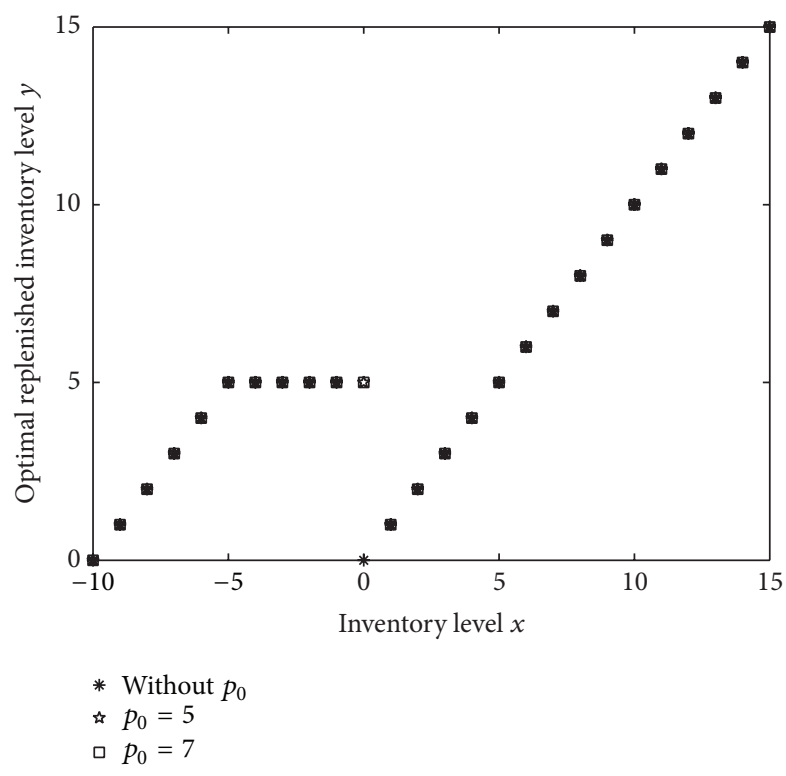

Figure 7: Optimal replenished inventory level $y$ for different $p_{0}$.

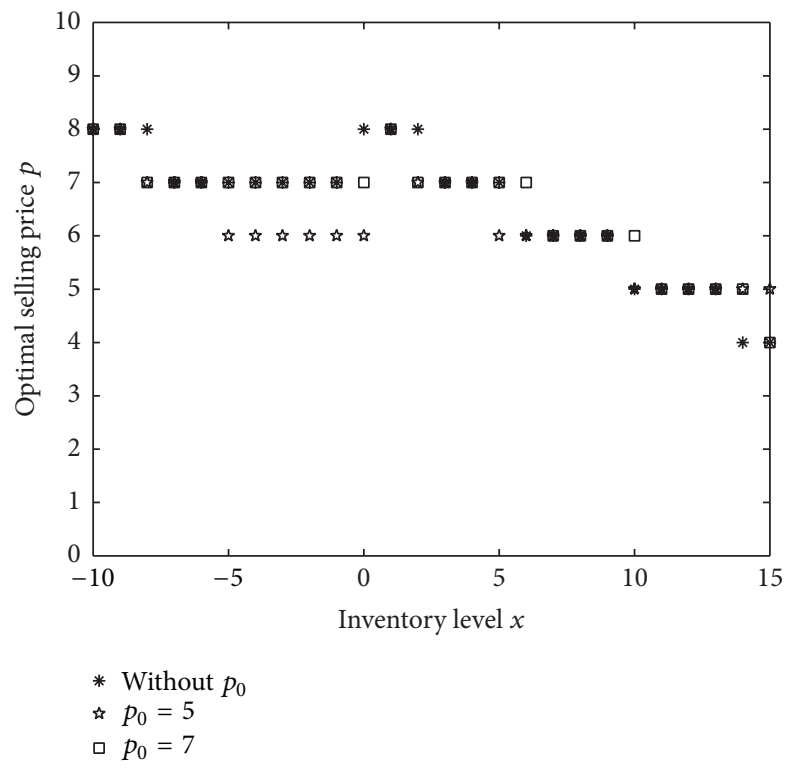

FIgURE 8: Optimal selling price $p$ for different $p_{0}$.

would be higher than the initial one under high inventory level.

In Figure 8, when the inventory level is 15 , the optimal selling price is 5 when the guide price is 5 , while the optimal selling price is 4 when the guide price is 7 . It leads to the following observation.

Observation 2. Higher guide price does not indicate higher optimal selling price.

4.4. Effect of Price Adjustment Cost Function. The effects of price adjustment cost on the optimal ordering and pricing policy are shown in Figures 9 and 10. We consider three cases:

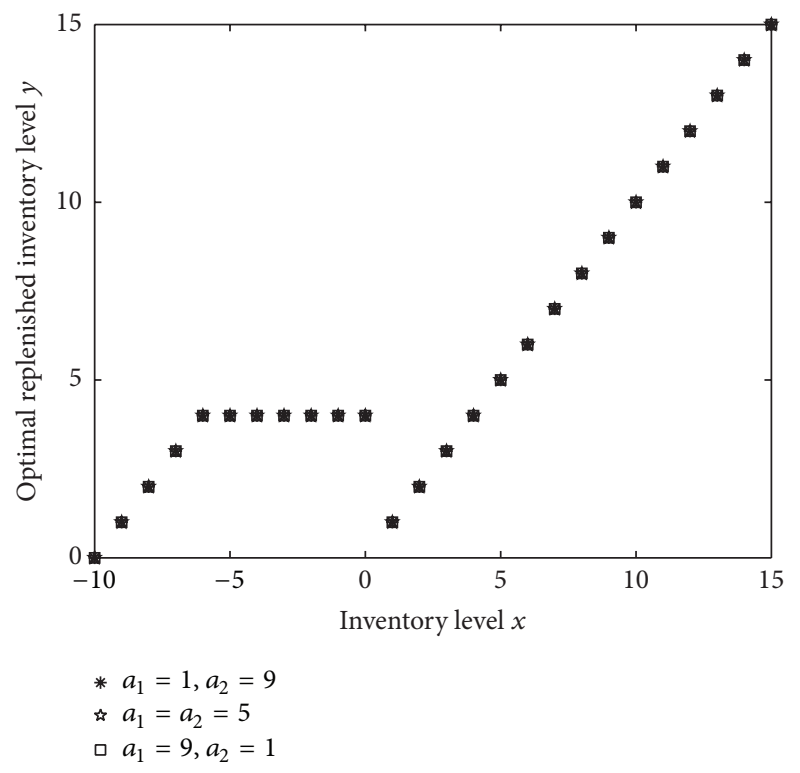

FIGURE 9: Optimal replenished inventory level $y$ for different $a_{1}$ and $a_{2}$.

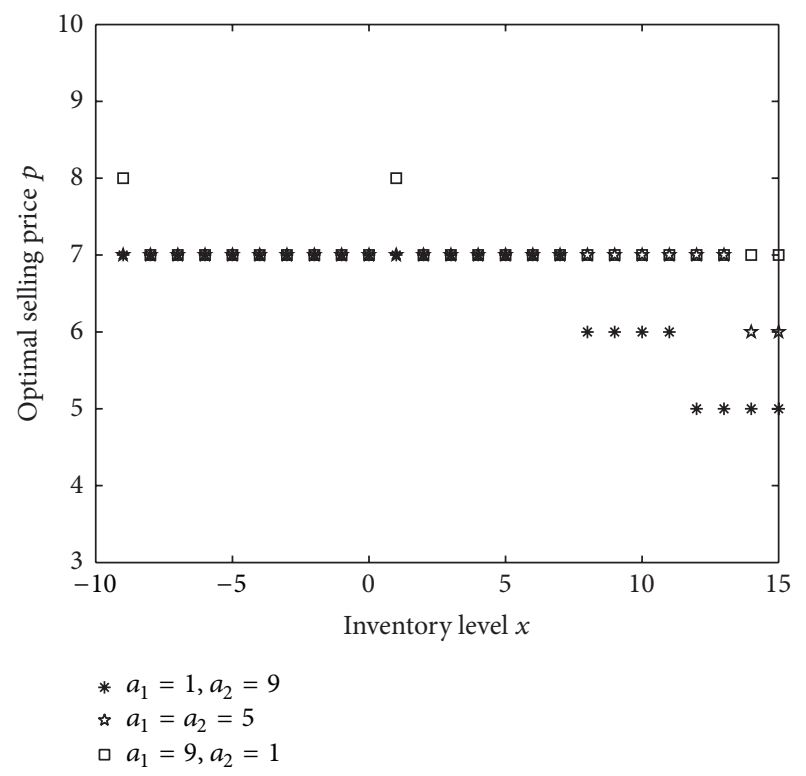

FIgURE 10: Optimal selling price $p$ for different $a_{1}$ and $a_{2}$.

$a_{1}=1, a_{2}=9, a_{1}=a_{2}=5$, and $a_{1}=9, a_{2}=1$. From Figure 9 , we find that the price adjustment cost function has no obvious effect on the optimal replenishment inventory level; however, it influences the optimal selling price obviously. $a_{1}<a_{2}$ implies that it would be more costly when the selling price is higher than the guide price. $a_{1}>a_{2}$ implies that it would be more costly when the selling price is smaller than the guide price. $a_{1}=a_{2}$ implies that it would be more costly when the selling price is not equal to the guide price. Hence, in Figure 10, under the same inventory level, the optimal selling price is the highest when $a_{1}>a_{2}$, while the optimal selling price is the smallest when $a_{1}<a_{2}$. 


\section{Conclusions}

In this paper, we consider a dynamic inventory control and pricing optimization problem in a periodic-review inventory system with fixed ordering cost and price adjustment cost. At the same time, the ordering quantity is limited. Here, we assume that the price adjustment cost functions are piecewise linear. We show that the optimal inventory control, similar to Chao et al. [4], is also partially characterized by $\left(s, s^{\prime}, p\right)$ policy in four regions, and the optimal pricing policy is dependent on the inventory level after the replenishment decision. From the numerical tests, we present some statistical analysis to study the effects of various parameters on the optimal control policy. For example, the higher setup cost $K$ implies lower inventory level at which the optimal ordering policy changes from ordering to not ordering and higher optimal selling price. When the inventory level is small, higher ordering capacity indicates high optimal replenished inventory level and lower optimal selling price. When the inventory level is high enough, the optimal ordering policy and selling price are the same under different inventory level. Optimal selling price would be closer to the guide price compared with the initial optimal selling price without guide price, while higher guide price does not indicate higher optimal selling price. Under the same inventory level, the optimal selling price is the highest when it would be more costly when the selling price is smaller than the guide price, while the optimal selling price is the smallest when it would be more costly when the selling price is larger than the guide price.

There are still many interesting issues worth studying in the future research. Our paper studied increasing convex price adjustment cost; exploring price adjustment cost function with more complicated form may be one of potential research directions. In our paper, the decision sequence is first inventory decision and then price decision, but in reality the firm may first set price to serve the target market and then build up the inventory. In this case, what is the optimal pricing and replenishment policy? Does the optimal control policy still possess the similar structure?

\section{Conflict of Interests}

The authors declare that there is no conflict of interests regarding the publication of this paper.

\section{Acknowledgments}

This work was supported in part by the National Natural Science Foundation of China under Grants nos. 71201128 and 71201127, Project for Training and Supporting Young Teachers in Shanghai Universities (no. ZZSDJ13007), and Leading Academic Discipline Project of Shanghai Dianji University (no. 10XKJ01).

\section{References}

[1] C. Shaoxiang and M. Lambrecht, "X-Y band and modified (s, S) policy," Operations Research, vol. 44, no. 6, pp. 1013-1019, 1996.
[2] G. Gallego and A. Scheller-Wolf, "Capacitated inventory problems with fixed order costs: some optimal policy structure," European Journal of Operational Research, vol. 126, no. 3, pp. 603-613, 2000.

[3] J.-L. Zhang, J. Chen, and C.-Y. Lee, "Coordinated pricing and inventory control problems with capacity constraints and fixed ordering cost," Naval Research Logistics, vol. 59, no. 5, pp. 376383, 2012.

[4] X. Chao, B. Yang, and Y. Xu, "Dynamic inventory and pricing policy in a capacitated stochastic inventory system with fixed ordering cost," Operations Research Letters, vol. 40, no. 2, pp. 99-107, 2012.

[5] J. J. Rotemberg, "Sticky prices in the United States," Journal of Political Economy, vol. 90, no. 6, pp. 1187-1211, 1982.

[6] D. Levy, M. Bergen, S. Dutta, and R. Venable, "The magnitude of menu costs: direct evidence from large U. S. supermarket chains," The Quarterly Journal of Economics, vol. 112, no. 3, pp. 790-825, 1997.

[7] M. E. Slade and Groupe de Recherche en Economie Quantitative d'Aix-Marseille, "Optimal pricing with costly adjustment: evidence from retail-grocery prices," The Review of Economic Studies, vol. 65, no. 1, pp. 87-107, 1998.

[8] V. Aguirregabiria, "The dynamics of markups and inventories in retailing firms," The Review of Economic Studies, vol. 66, no. 2, pp. 275-308, 1999.

[9] M. Bergen, M. Ritson, S. Dutta, D. Levy, and M. Zbarachi, "Shattering the myth of costless price changes," European Management Journal, vol. 21, no. 6, pp. 663-669, 2003.

[10] M. J. Zbaracki, M. Ritson, D. Levy, S. Dutta, and M. Bergen, "Managerial and customer costs of price adjustment: direct evidence from industrial markets," The Review of Economics and Statistics, vol. 86, no. 2, pp. 514-533, 2004.

[11] X. Chen, S. X. Zhou, and Y. Chen, "Integration of inventory and pricing decisions with costly price adjustments," Operations Research, vol. 59, no. 5, pp. 1144-1158, 2011. 


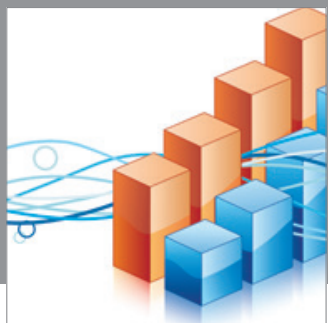

Advances in

Operations Research

mansans

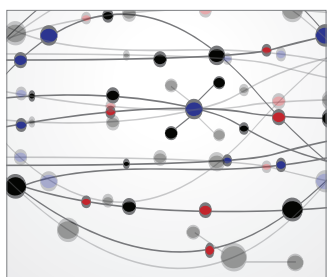

The Scientific World Journal
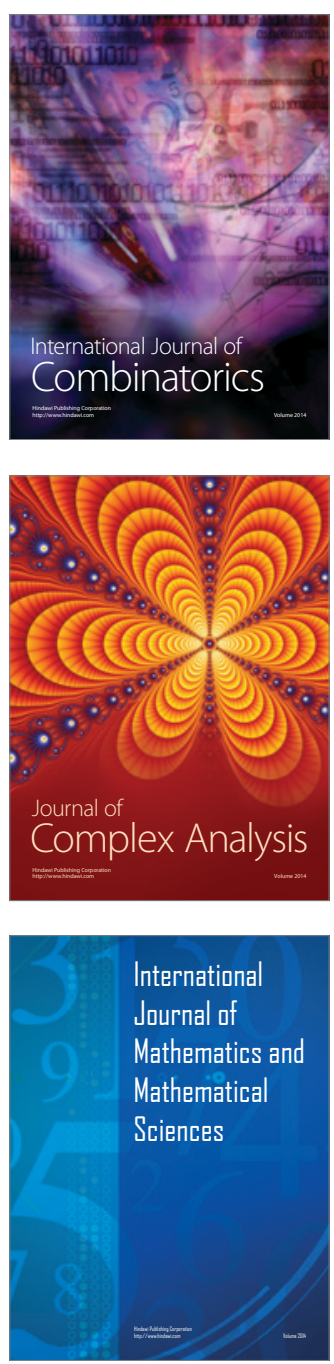
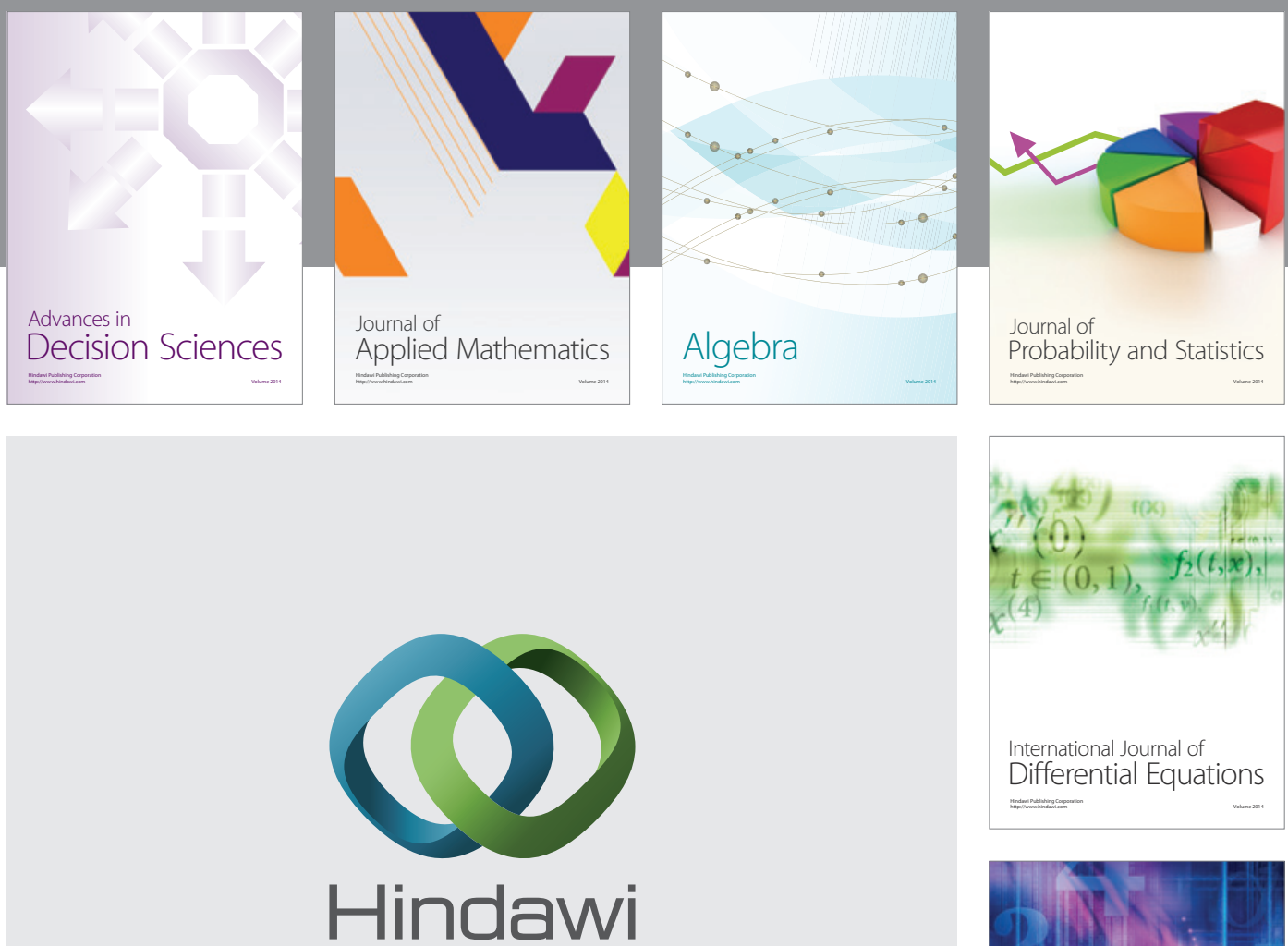

Submit your manuscripts at http://www.hindawi.com
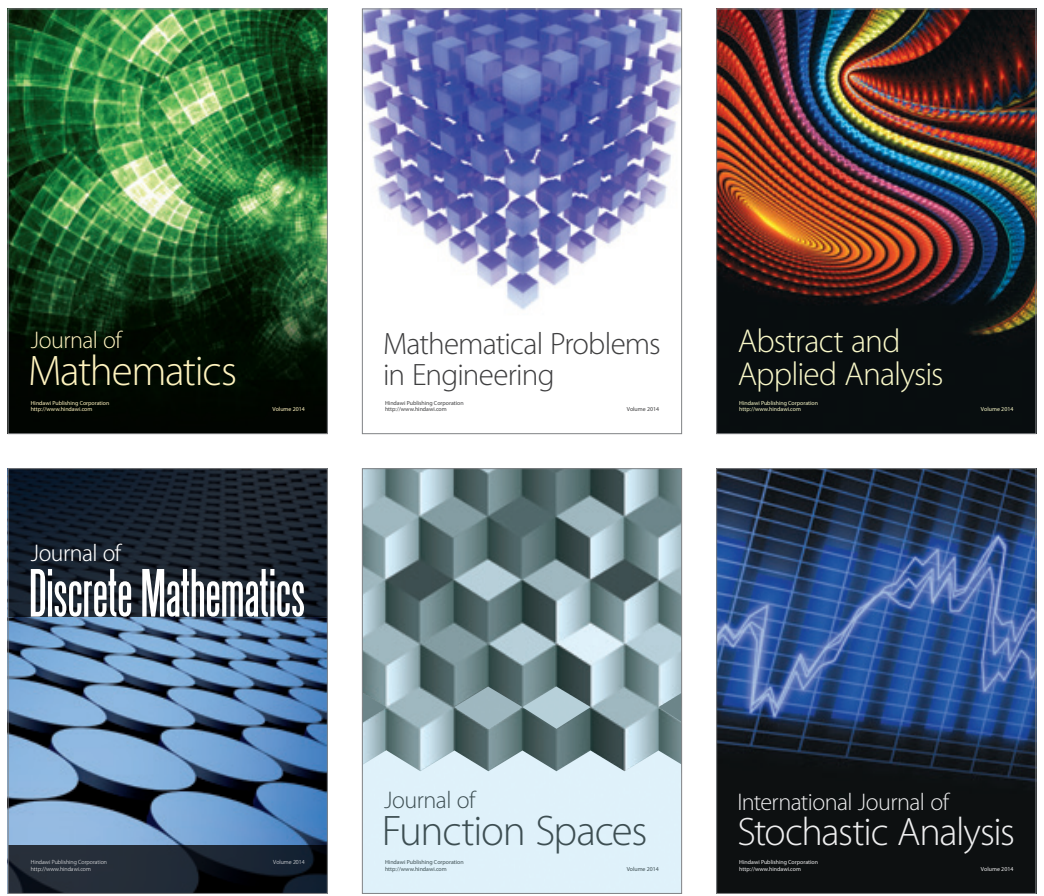

Journal of

Function Spaces

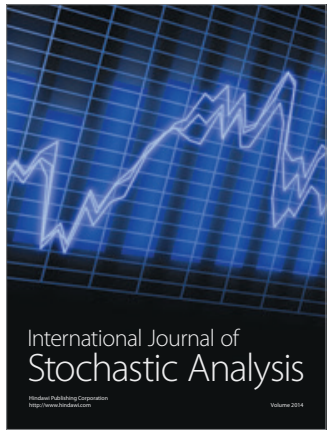

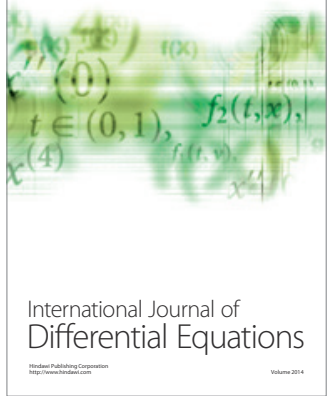
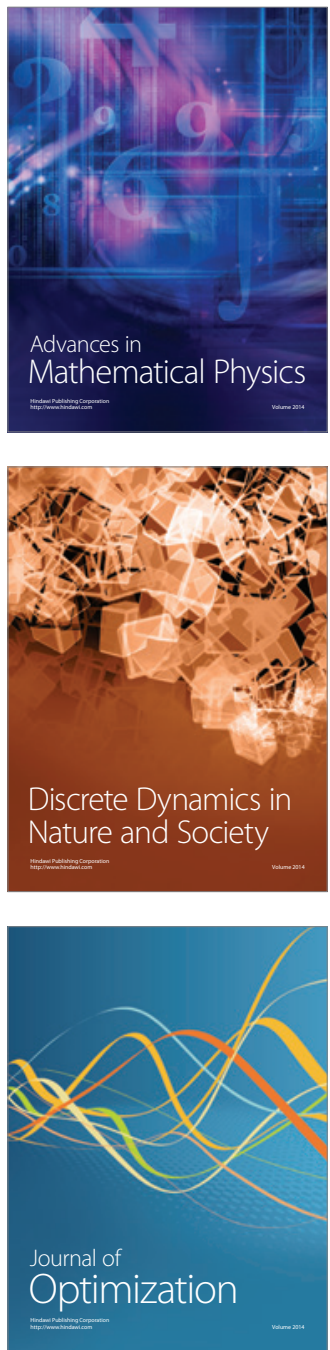